\title{
DESAIN DIDAKTIS PADA HUKUM ARCHIMEDES BERDASARKAN HAMBATAN BELAJAR PESERTA DIDIK PADA SEKOLAH MENENGAH ATAS KELAS X
}

\author{
Achmad Ali Yusuf ${ }^{1}$ \\ ${ }_{1}^{1}$ Program Studi Pendidikan Fisika Fakultas Tarbiyah dan Keguruan UIN Sunan Gunung Djati \\ Bandung Jl. A H. Nasution No 105 Bandung \\ E-mail: aliyusuf@gmail.com
}

\begin{abstract}
ABSTRAK
Penelitian Desain Didaktis bertujuan menyusun desain pembelajaran berdasarkan hambatan belajar yang muncul pada peserta didik. Desain yang dikembangkan dalam penelitian ini adalah desain pembelajaran pada materi Hukum Archimedes. Sampel dalam penelitian ini adalah kelas X-IPA2, X-IPA5, dan X-IPA6. Sample ditentukan berdasarkan teknik purposive sampling. Prosedur dalam penelitian desain didaktis ini adalah diawali dengan melakukan Tes Kemampuan Responden (TKR) awal untuk mengetahui hambatan apa saja yang muncul pada materi Hukum Archimedes. Setelah diketahui hambatan-hambatan yang dialami oleh peserta didik, langkah selanjutnya adalah menyusun desain didaktis dengan mengacu pada hambatan belajar yang muncul pada TKR awal. Implementasi desain dilakukan secara paralel pada kelas X-IPA. Desain didaktis yang diimplementasikan selalu mengalami revisi pada setiap pertemuannya dengan tujuan agar hambatan yang muncul dapat diminimalisasi. Berdasarkan hasil penelitian dapat disimpulkan bahwa desain didaktis yang disusun dapat meminimalisasi hambatan belajar yang muncul pada peserta didik. Meskipun belum secara utuh dan dapat dijadikan sebagai salah satu rekomendasi desain pembelajaran pada materi Hukum Archimedes.
\end{abstract}

Kata kunci: Didactical Design Research (DDR), Hambatan Belajar Peserta Didik, Hukum Archimedes.

\section{ABSTRACT}

The didactical design Research aims to compile learning design based on learning barriers that arise in learners. The design developed in this study was the design of the learning on Archimedes 'legal material. The samples in this study are X-IPA2, X-IPA5, and X-IPA6 classes. Samples are determined based on purposive sampling techniques. The procedure in this didactic design study was initiated by conducting an early Respondent proficiency test (TKR) to determine what obstacles appeared on Archimedes ' legal material. Having known the obstacles experienced by the learners, the next step is to draft the didactic design by referring to the learning barriers that arise in the early TKR. Design implementation is done in parallel in X-IPA class. The didactical design that was implemented always underwent revisions to each meeting with the aim that the obstacles could be minimized. Based on the results of the study it can be concluded that the designed didactical design can minimize the learning barriers that arise in the learners. Although not yet as a whole, it can be used as one of the design recommendations on Archimedes 'legal material

Keywords: representation, single modes representation, translation among modes of representation, multiplerepresentation

DOI: http://dx.doi.org/10.15575/jtlp.v2i2.6592

Received: 20 Juli 2017 ; Accepted: 25 Agustus 2017 ; Published: 1 September 2017 


\section{PENDAHULUAN}

Hambatan belajar yang dialami oleh peserta didik dapat diantisipasi dengan menggunakan desain didaktis. Penelitian yang telah menggunakan desain didaktis adalah penelitian yang dilakukan oleh Stefani (2015: 76), hasil dari penelitian ini menyatakan bahwa hambatan yang dimiliki siswa telah mengalami penurunan persentasenya melalui implementasi desain didaktis yang dibuat berdasarkan hambatan belajar siswa. Senada dengan Stefani, Budiansah (2015: 80) menyatakan bahwa hasil dari implementasi desain didaktis dapat mengurangi hambatanhambatan yang dialami oleh siswa. Kemudian Penelitian Michele Artigue dalam "Didactical Design In Mathematics Education".

Penelitian lain yang menggunakan desain didaktis adalah penelitian yang dilakukan oleh Suryana dan Karlimah (2013: 1), dari penelitiannya didapatkan hasil bahwa hambatan belajar siswa dapat teratasi dengan menggunakan Penelitian Desain Didaktis (Didactical Design Research). Hambatan yang pada awalnya muncul, menjadi tidak muncul kembali setelah diterapkannya DDR.

\section{METODE PENELITIAN}

Populasi dari penelitian ini adalah kelas $\mathrm{X}$ SMAN 1 Cililin. Kemudian dengan menggunakan teknik purposive sampling sehingga dipilih kelas X2, X5, dan X6 SMAN 1 Cililin sebagai sampel. Teknik ini digunakan karena mengingat keterbatasan waktu, tenaga dan dana sehingga tidak dapat mengambil sampel yang besar dan jauh (Arikunto, 2010: 183). Metode yang digunakan dalam penelitian ini adalah metode kualitatif deskriptif. Metode kualitatif dengan pendekatan studi deskriptif dipilih karena peneliti membutuhkan data yang mendalam. Data yang dimaksud adalah data mengenai hambatan belajar peserta didik. Dengan mengetahui secara mendalam, maka kita dapat membuat desain pembelajaran yang sesuai dengan hambatanhambatan yang muncul. Untuk mendapatkan data hambatan awal adalah dengan menggunakan Tes Kemampuan Responden (TKR) terhadap kelas yang telah mendapatkan materi.

\section{HASIL DAN PEMBAHASAN}

\section{Hambatan Belajar}

Hambatan belajar diketahui dengan memberikan soal tes essay kepada peserta didik yang telah mendapatkan pembelajaran materi Hukum Archimedes. Soal Tes Kemampuan Responden (TKR) awal diberikan kepada kelas XI IPA 2. Hasil TKR awal didapatkan beberapa hambatan belajar peserta didik, hambatan belajar tersebut adalah: Peserta didik Soal pertama yang digunakan adalah berupa soal konsep Hukum Archimedes. Hambatan yang muncul adalah: (1) Peserta didik tidak dapat menentukan hukum yang berkaitan dengan gambar, (2) tidak dapat menjelaskan bunyi Hukum Archimedes, (3) tidak dapat membedakan bacaan pada neraca, dan (4) tidak dapat menjelaskan perbedaan bacaan pada neraca. Soal kedua adalah soal tentang analisis gaya-gaya yang bekerja pada Hukum Archimedes. Hambatan yang muncul adalah: (1) Peserta didik tidak dapat menggambarkan gaya-gaya yang bekerja pada benda, (2) tidak dapat menyebutkan gaya-gaya yang bekerja pada benda, dan (3) tidak dapat menuliskan persamaan Archimedes. Soal ketiga adalah soal mengenai hubungan massa jenis benda dengan massa jenis fluida berdasarkan Hukum Archimedes. Hambatan belajar pada soal nomor tiga adalah: (1) Peserta didik tidak dapat membedakan posisi benda yang tercelup dalam fluida dan (2) tidak dapat menjelaskan perbandingan antara massa jenis benda dengan fluida. Soal keempat merupakan soal yang berbentuk matematis. Hambatan yang muncul adalah: (1) peserta didik tidak dapat menyebutkan besaran-besaran yang diketahui pada soal, (2) tidak dapat menentukan besar gaya Archimedes pada saat benda tercelup sebagian, dan (3) tidak dapat menentukan besar gaya Archimedes pada saat benda tercelup seluruhnya. Soal kelima merupakan soal penerapan Hukum Archimedes pada kehidupan sehari-hari. Soal nomor lima menyajikan contoh aplikasi Hukum Archimedes berupa kapal selam. Kemudian didapatkan hambatan pada soal nomor lima adalah (1) tidak dapat menjelaskan prinsip kerja kapal selam. 


\section{Desain Didaktis}

Berdasarkan hambatan peserta didik yang muncul, maka dibuat desain pembelajaran yang dapat meminimalisasi hambatan tersebut. Desain didaktis yang dibuat diimplementasikan di tiga kelas $\mathrm{X}$ dengan tujuan agar menghasilkan desain pembelajaran yang baik dan dapat meminimalisasi hambatan belajar dengan maksimal. Dalam implementasinya desain yang telah diimplementasikan mendapatkan revisi terlebih dahulu sebelum melakukan implementasi selanjutnya, sehingga kekurangan yang muncul dapat teratasi dan tidak terulang pada implementasi selanjutnya. Dengan harapan didapat desain didaktis yang sesuai dengan materi Hukum Archimedes dan hambatan belajar peserta didik dapat terminimalisasi.

Berdasarkan implementasi desain pertemuan pertama (P1), pertemuan kedua (P2) dan pertemuan ketiga (P3) hambatan belajar yang dialami oleh peserta didik mengalami penurunan. Hasil penurunan hambatan tersebut adalah sebagai berikut.

\begin{tabular}{|c|c|c|c|c|c|}
\hline $\begin{array}{c}\text { No } \\
\text { Soa } \\
1\end{array}$ & $\begin{array}{c}\text { No } \\
\text { Hambata } \\
n\end{array}$ & $\begin{array}{c}\text { TKR } \\
\text { Awa } \\
\text { l }\end{array}$ & P1 & P2 & P3 \\
\hline \multirow[t]{4}{*}{1} & 1 & $\begin{array}{l}26 \\
\% \\
\end{array}$ & $18 \%$ & $2.8 \%$ & $2.6 \%$ \\
\hline & 2 & $\begin{array}{l}77 \\
\% \\
\end{array}$ & $\begin{array}{r}57.9 \\
\% \\
\end{array}$ & $\begin{array}{r}38.9 \\
\% \\
\end{array}$ & $\begin{array}{r}36.8 \\
\% \\
\end{array}$ \\
\hline & 3 & $\begin{array}{l}37 \\
\% \\
\end{array}$ & $\begin{array}{r}30.8 \\
\% \\
\end{array}$ & $\begin{array}{r}41.7 \\
\% \\
\end{array}$ & $2.6 \%$ \\
\hline & 4 & $\begin{array}{l}49 \\
\% \\
\end{array}$ & $\begin{array}{r}63.2 \\
\% \\
\end{array}$ & $\begin{array}{r}41.7 \\
\% \\
\end{array}$ & $\begin{array}{r}35.9 \\
\% \\
\end{array}$ \\
\hline \multirow[t]{3}{*}{2} & 1 & $\begin{array}{l}89 \\
\%\end{array}$ & $\begin{array}{r}41.0 \\
\%\end{array}$ & $\begin{array}{r}27.8 \\
\%\end{array}$ & $\begin{array}{r}28.9 \\
\%\end{array}$ \\
\hline & 2 & $\begin{array}{l}71 \\
\% \\
\end{array}$ & $\begin{array}{r}47.4 \\
\% \\
\end{array}$ & $\begin{array}{r}25.6 \\
\% \\
\end{array}$ & $\begin{array}{r}13.9 \\
\% \\
\end{array}$ \\
\hline & 3 & \begin{tabular}{|l}
74 \\
$\%$ \\
\end{tabular} & $50 \%$ & $20 \%$ & $8.3 \%$ \\
\hline \multirow[t]{2}{*}{3} & 1 & $\begin{array}{l}34 \\
\% \\
\end{array}$ & $33 \%$ & $5.6 \%$ & $0 \%$ \\
\hline & 2 & $\begin{array}{l}51 \\
\% \\
\end{array}$ & $\begin{array}{r}28.2 \\
\% \\
\end{array}$ & $\begin{array}{r}33.3 \\
\% \\
\end{array}$ & $7.9 \%$ \\
\hline
\end{tabular}

\begin{tabular}{rrrrrr}
\hline 4 & 1 & 57 & 10.3 & $2.8 \%$ & $0 \%$ \\
& & $\%$ & $\%$ & & \\
\cline { 2 - 6 } & 2 & 86 & 35.8 & 26.3 & \multirow{2}{*}{$5.6 \%$} \\
& & $\%$ & $\%$ & $\%$ & \\
\hline 3 & 89 & 35.9 & 26.3 & 13.9 \\
& & $\%$ & $\%$ & $\%$ & $\%$ \\
\hline 5 & 1 & 77 & 51.3 & 39.5 & \multirow{2}{*}{$2.8 \%$} \\
& & $\%$ & $\%$ & $\%$ & \\
\hline
\end{tabular}

Hambatan belajar yang mengalami kenaikan diantaranya adalah soal nomor satu poin ketiga pada implementasi kedua. hambatan pada poin ini yaitu peserta didik tidak dapat membedakan bacaan pada neraca (saat mengukur berat benda di udara dan di fluida). Kenaikan pada hambatan ini adalah sebesar 10.9\%. Hambatan ini mengalami kenaikan karena waktu yang digunakan peserta didik untuk melakukan praktikum hanya sedikit. Akibatnya peserta didik cukup terburu-buru dalam melakukan praktikum sehingga kemampuan dalam melakukan pengukuran menjadi kurang baik. Hambatan selanjutnya yang mengalami kenaikan adalah soal nomor satu poin keempat pada implementasi pertama. Hambatan pada poin ini yaitu peserta didik tidak dapat menjelaskan alasan kenapa terjadi perbedaan bacaan pada neraca. Kenaikan hambatan ini terjadi karena pada saat menjelaskan guru kurang memberikan penekanan bahwa benda yang berada di air akan lebih ringan (berat semu) dibandingkan benda yang berada di udara.

Keterlaksanaan desain pembelajaran salah satunya dilihat dari lembar observasi kegiatan guru dan peserta didik. lembar observasi diisi oleh tiga observer. Keterlaksanaan kegiatan guru dan peserta didik selama tiga pertemuan ditunjukkan oleh tabel berikut.

\begin{tabular}{ccccc}
\hline \multirow{2}{*}{$\begin{array}{c}\text { Pertemu } \\
\text { an }\end{array}$} & \multicolumn{2}{c}{ Kegiatan Guru } & \multicolumn{2}{c}{$\begin{array}{c}\text { Kegiatan } \\
\text { Peserta Didik }\end{array}$} \\
\cline { 2 - 5 } & $\mathbf{\%}$ & $\begin{array}{c}\text { Interpret } \\
\text { asi }\end{array}$ & $\mathbf{\%}$ & $\begin{array}{c}\text { Interpret } \\
\text { asi }\end{array}$ \\
\hline 1 & 95. & $\begin{array}{c}\text { Sangat } \\
\text { Baik }\end{array}$ & $\begin{array}{c}92 . \\
6\end{array}$ & $\begin{array}{c}\text { Sangat } \\
\text { Baik }\end{array}$ \\
\hline
\end{tabular}




\begin{tabular}{ccccc}
\hline \multirow{2}{*}{$\begin{array}{c}\text { Pertemu } \\
\text { an }\end{array}$} & \multicolumn{2}{c}{ Kegiatan Guru } & \multicolumn{2}{c}{$\begin{array}{c}\text { Kegiatan } \\
\text { Peserta Didik }\end{array}$} \\
\cline { 2 - 5 } & $\mathbf{\%}$ & $\begin{array}{c}\text { Interpret } \\
\text { asi }\end{array}$ & $\begin{array}{c}\text { Interpret } \\
\text { asi }\end{array}$ \\
\hline 2 & 96. & Sangat & 95. & $\begin{array}{c}\text { Sangat } \\
\text { Baik }\end{array}$ \\
& 9 & 6 & Baik \\
\hline 3 & 99. & Sangat & 98. & Sangat \\
& 0 & Baik & 9 & Baik \\
\hline \multirow{2}{*}{ Rata-rata } & 97. & Sangat & 95. & Sangat \\
& 2 & Baik & 7 & Baik \\
\hline
\end{tabular}

\section{KESIMPULAN}

Berdasarkan hasil Penelitian Desain Didaktis (Didactical Design Research) yang telah dilakukan dapat disimpulkan bahwa hambatan belajar peserta didik pada Hukum Archimedes adalah: (a) Peserta didik tidak mampu menjelaskan bunyi hukum archimedes. (b) Tidak mampu menjelaskan perbedaan berat benda ketika benda berada di udara dan di fluida. (c) Tidak mampu menggambarkan dan menyebutkan gaya-gaya yang bekerja pada benda tercelup dalam air. (d) Tidak mampu membedakan posisi benda yang tercelup dalam air dan menjelaskan perbandingan massa jenisnya. (e) Tidak mampu menentukan besar gaya archimedes pada saat benda tercelup sebagian maupun tercelup seluruhnya. (f) Tidak mampu menjelaskan prinsip kerja alat yang menggunakan hukum archimedes.

Berdasarkan hasil desain didaktis awal dan implementasi di tiga kelas, desain didaktis untuk hukum archimedes adalah: (a) Guru mengarahkan peserta didik untuk melakukan percobaan langsung sehingga memahami hukum archimedes berdasarkan percobaan yang dilakukan. (b) Peserta didik melakukan pengukuran benda di udara dan di air menggunakan neraca pegas. (c) Guru menggambarkan benda yang sedang tercelup kemudian meminta peserta didik untuk menggambarkan gaya-gaya apa saja yang mempengaruhi benda tersebut. (d) Guru menggambarkan benda yang sedang melayang, terapung dan tenggelam kemudian meminta peserta didik untuk menuliskan perbandingan massa jenis antara benda dan air. (e) Guru memberikan latihan soal untuk dikerjakan oleh peserta didik dan membahasnya bersama-sama. (f) Guru meminta peserta didik untuk menyebutkan dan menjelaskan benda-benda yang menggunakan prinsip kerja Archimedes.

Keterlaksanaan menggunakan desan dedaktis pada materi hukum archimedes termasuk kedalam kategori yang sangat baik dengan ratarata keterlaksanaan $97.23 \%$ untuk aktivitas guru dan $95.70 \%$ untuk aktivitas peserta didik.

Adapun saran untuk penelitian selanjutnya adalah penelitian desain didaktis alangkah lebih baik dilakukan pada satu kelas, sehingga hambatan yang dialami oleh peserta didik dapat diatasi dengan pemberian perlakuan tertentu kepada peserta didik. Dalam tahap analisis sebelum pembelajaran, sebaiknya peneliti membuat antisipasi didaktis pada setiap situasi didaktis secara mendalam dan terperinci sehingga memudahkan guru untuk mengatasi hambatan belajar peserta didik. Dalam taham implementasi desain, observasi kelas sebaiknya dilakukan oleh observer ahli seperti guru. Dengan observer ahli, diharapkan temuan-temuan hasil observasi dapat lebih tajam dan mendalam. Dalam tahap analisis retrosfektif, peneliti sebaiknya lebih jeli dalam menganalisis keterkaitan antara hasil TKR, implementasi desain didaktis dan juga analisis metapedadidaktis

\section{DAFTAR PUSTAKA}

Arikunto, Suharsimi. (2010). Prosedur Penelitian Suatu Pendekatan Praktik. Yogyakarta: Rineka Cipta.

Budiansah, Indra. (2015). Desain Didaktis Pembelajaran Konsep Azas Black dan Perpindahan Kalor Berdasarkan Hambatan Belajar Siswa pada Tingkat Sekolah Menengah Atas Kelas X. Skripsi. Bandung: UPI. Tidak diterbitkan.

Stefani, Rahellia. (2015). Desain Didaktis Pembelajaran Konsep Energi dan Energi Kinetik Berdasarkan Kesulitan Belajar Siswa 
pada Sekolah Menengah Atas. [Online]. Tersedia: $\quad$ http://jpppf.fisika-unj.ac.id/ index.php/jpppf/article/ view/11 [diakses 5 Desember 2015].

Suryana, Y dan Karlimah. (2013). Pengembangan Bahan Ajar KPK dan FPB: Model Desain Didaktis Pada Pembelajaran Matematika di Sekolah Dasar. Vol. 4 No. 3 Desember 2013. [Online]. Tersedia: http://jurnal.upi.edu/1957/view/1957/ pengembangan-bahan-ajar-kpk-dan-fpb:-model-desain-didaktis-pada-pembelajaranmatematika-di-sekolah-dasar.html [diakses 6 Desember 2015] 